\section{Stem cells on South African shores: Proposed guidelines for comprehensive informed consent}

To the Editor: In October 2012, Shinya Yamanaka and Sir John Gurdon were awarded the Nobel Prize in Physiology or Medicine for their pioneering research into the reprogramming of mature cells into a pluripotent state. The technology developed by Yamanaka and colleagues allows researchers to turn terminally differentiated somatic cells back into a stem-cell state. ${ }^{1}$ These induced pluripotent stem cells (iPSCs) can be cultured indefinitely in the laboratory, and can undergo directed differentiation into any cell type of interest. This is highly beneficial for disease-modelling studies, since researchers are able to culture cells that are not normally obtainable, such as neurons or retinal cells. Furthermore, the differentiated cells can be used to test potential therapies in patient-derived cells, and may even be used for future therapeutic cell transplantation.

iPSC research is no longer a 'foreign' technology, with laboratories from at least two South African institutions employing these methods for 'disease-in-a-dish' modelling. Given the seemingly endless possibilities for future iPSC-based research, we wish to highlight the challenges associated with obtaining comprehensive informed consent from research participants. A recent review from the National Institutes of Health in the USA outlined the standards, policies, protocols and regulations required for cell-based therapies, and addressed specimen collection for iPSC research. ${ }^{2}$ The authors pointed out that providing accurate information about what will not be done with a research participant's specimen is almost impossible, given the rapid advances in research. We propose that the informed consent documentation must be explicit when addressing these matters. In South Africa, for example, definitive assurance could be given that germline cell derivatives and reproductive applications will not be attempted or developed with the generated iPSCs, as current legislation prohibits certain uses of biological samples, such as the reproductive cloning of humans (National Health Act 61/2003: 57(1)). These assurances will need to be reviewed regularly, however, so that research possibilities are not stultified by bureaucracy and avoidance of debate.

In many respects, iPSC research seems to provide more questions than answers and this creates a new challenge for researchers and research ethics committees. ${ }^{3}$ A balance must be found between consent that is too broad and indistinct, or too narrow, which may hinder future research prospects. Some commentators favour a 'tiered' approach to consent, which allows participants to consent to specific uses, and to stipulate their wishes regarding banking and sharing their biological material with other researchers, and whether they wish to be re-contacted in the event that further use of their samples is needed. This would enable individuals to opt out of sensitive areas such as gamete formation, reproductive research, commercialisation and genetic manipulation.

In the South African context, we need to determine efficacy and safety by using iPSCs as pre-clinical cellular models, in preparation for future therapeutic development and human clinical trials. By addressing the scientific, legal and ethical implications of establishing and using iPSCs in the laboratory, we can use this time constructively and productively to develop prospective policies for the use of iPSCs in future therapeutic applications. ${ }^{4}$

\section{Jacquie Greenberg}

\section{Danielle Smith}

Division of Human Genetics, Department of Clinical Laboratory Science, Faculty of Health Sciences, University of Cape Town

jacquie.greenberg@uct.ac.zo

\section{Anne Pope}

Department of Private Law, Faculty of Law, University of Cape Town

\begin{abstract}
Robinton DA, Daley GQ. The promise of induced pluripotent stem cells in research and therapy Nature 2012;481(7381):295-305. [http://dx.doi.org/10.1038/nature10761]

2. Lowenthal J. Lipnick S, Rao M. Hull SC. Specimen collection for induced pluripotent stem cell research: Harmonizing the approach to informed consent. Stem Cells Translational Medicine 2012;1(5):409Harmonizing the approach to informed consent. Stem Cells Translational Medicine 2012;1(5):409-
421. [http://dx.doi.org/10.5966/sctm.2012-0029]
Aalto-Setälä K. Conklin BR, Lo B. Obtaining consent for future research with induced pluripotent

Aalto-Setälä K, Conklin BR, Lo B. Obtaining consent for future research with induced pluripoten cells: Opportun

pbio.1000042] FPCS for personalized medicine: what will it take for Africa? Trends Mol Med 2012;18(12): 695-699. [http://dx.doi.org/10.1016/j.molmed.2012.10.005]
\end{abstract}

S Afr Med J 2013;103(1):6. DOI:10.7196/SAMJ.6532

\section{Poor maternal outcomes}

To the Editor: I was surprised to read that Schoon and Motlolometsi were not able to find any clear job description or scope of practice for advanced midwives (ADMs) in this country. ${ }^{1}$ Both were clearly defined in KwaZulu-Natal in 1980, when the first ADM training programme was established at King Edward VIII Hospital, Durban.

The programme was co-designed by the Nursing College and the Community Obstetrics Department of the University of Natal medical school. The starting points used were the needs then apparent in the province's maternity services and the framework of regulations governing the Advanced Diploma in Midwifery and Neonatal Science. The scope of practice and job description were further developed by DEPAM (the Decentralised Education Programme for Advanced Midwives), funded by the Kellogg Foundation, and the university Department of Nursing's postgraduate programme. Only competent midwives were selected for the course.

The skills base aimed at developing nurse practitioners who would be able to do the following, in co-operation with the medical staff:

- adequately assess the health status of antenatal, intrapartum and postnatal women, and their neonates

- manage patients attending the high-risk antenatal clinics for women with hypertension, multiple pregnancies, previous caesarean section, gestational diabetes, etc.

- manage these women in labour with the assistance of the medical staff

- provide excellent postnatal care to 6 weeks postpartum

- monitor the standard of obstetric care, including organising and running monthly perinatal mortality meetings, and offer feedback to the district staff regarding all referrals

- provide ongoing in-service education for all midwives in the hospital and its referring clinics, later using the Perinatal Education Programme (PEP) $)^{2}$ material

- locate and train traditional midwives to bring them into the care net

- act as facilitators in building a perinatal care team in the unit.

We followed the first graduates from the diploma course back to their hospitals in northern KZN in 1981, and helped them to apply their skills there. Many of these nurse practitioners faced resistance from nursing managers, but most medical officers in rural units were grateful for their help, and bought into the concept. At that time, the district hospital system was fully integrated, and the ADMs were able to move around from each district hospital to its clinics, supporting and upgrading midwives' skills.

The impact of these enthusiastic women with medical support was impressive. Regional perinatal mortality dropped from 46/1 000 to 25/1 000 and the maternal mortality rate fell to 107/100 000 in 1993, in spite of political turmoil in the province.

Unfortunately, the lack of a career path in clinical nursing care meant that many ADMs were later 'promoted' to administrative posts. Their impact was also vastly reduced by the new Health Act, which replaced their passionate hands-on clinical leadership with cadre-deployment bureaucrats who have no direct responsibility for obstetric outcomes. 
Therein lies a lesson for those wishing to improve the lot of mothers and babies in South Africa.

\author{
J V Larsen \\ Howick \\ jon.larsen@iuncapped.co.za
}

L Schoon, MG, Motlolometsi MWA. Poor maternal outcomes: a factor of poor professional systems design. S Afr Med J 2012;102(10):784-786. [http://dx.doi.org/10.7196/SAMJ.6130]

Woods DL, Theron GB. Addressing poor maternal and perinatal outcomes. S Afr Med J 2012;102(10):786 [http://dx.doi.org/10.7196/SAMJ.6126]

S Afr Med J 2013;103(1):6-7. DOI:10.7196/SAMJ.6476

\section{Can a new paediatric sub-specialty improve child health in South Africa?}

To the Editor: David Hall (my previous Professor of Child Health in the UK, who always hoped to make a contribution to child health in South Africa) and others emphasise the importance of the child health approach in delivering healthcare for children.

The suggested sub-specialty would help to change the mindset of South African doctors from believing that paediatric care and child healthcare are the same. The former focuses on ill health (ubisi seluchithekile 'the horse has already bolted'), while the latter would suggest a more comprehensive approach to the needs of children, i.e. crisis intervention, prevention and health promotion. The health policy of the present South African government implies such an approach, although serious management constraints have prevented implementation.

The Health Development Institute (HDI), based in Mitchell's Plain, Cape Town, piloted a community-based healthcare model with a comprehensive approach to the provision of healthcare for children in backyard crèches. ${ }^{2}$ The HDI undertook a major project to assess the needs of these children (physical, including dental). Among other findings, the survey identified service gaps for this population, and made suggestions as to how they could be bridged. This project demonstrated a communitybased approach to healthcare of children by translating the individual needs of the child to the needs of the community by integrating clinical practice and population health. Sensitising family doctors to population health would also help them to appreciate the distinction between health inequalities (by and large influenced by personal lifestyles) and health inequities (influenced by social factors that require appropriate health, economic and educational policies to redress). ${ }^{3}$

However, the translation of clinical encounters to a population approach will require a pro-active public health discipline to complement such a paradigm shift for these family prctitioners. Some years ago I raised this issue with Dr Hendrik Hanekom (then Secretary-General of the South African Medical Association) when I was serving on the Board of SAMA, suggesting the setting up of a public health consultancy within SAMA. Given that the objectives of SAMA include encouraging involvement in health promotion and education, and influencing the healthcare environment to meet the needs and expectations of the community by promoting improvements in health reform policy and legislation, such a sub-committee would enable SAMA to play its rightful role as the custodians of the nation's health.

\section{E M Mankazana}

15 Beech Drive, Daventry, Northants, UK

mxomank@doctors.net.uk

1. Swingler G, Hendricks M, Hall D, et al. Can a new paediatric sub-specialty improve child health in South Africa? S Afr Med J 2012;102(9):738-739. [http://dx.doi.org/10.7196/SAMJ.5714]

2. Mankazana EM. From Exile to Exile - an Autobiography of a Black South African Professional Authorhouse, 201
3. Moscrop A. Health inequalities in primary care: Time to face justice. Br J Gen Pract 2012;62(601). http:/ www.rcgp.org.uk/publications/bjgp/discussion-forum.aspx (accessed 30 November 2012).

S Afr Med J 2013;103(1):7. DOI:10.7196/SAMJ.6318

\section{When will we escape from the medical funding industry's 'spin'?}

To the Editor: I am a specialist in private practice. A patient recently asked for a quotation for an operation, and I supplied her with the relevant codes and pricing structures. As we have no contracts with medical aids she was advised to contact her insurer to ascertain which payments she could expect. Obtaining this information from them was a challenge. She was informed that they could not provide an estimate as to which part of the cost they would cover (thankfully, she was not regaled with the usual 'we refund 100\%, 200\% and even $300 \%$ of the bill'). She was also told that they had not heard of code 0023, which is the anaesthetic modifier for time that must feature on an anaesthetic account and with which most funders are familiar.

This anecdote illustrates the wilful or unintentional incompetence of the medical funding industry. At the same time we are bombarded with media reports from the Minister of Health, the Editor of the $S A M J$ and the Board of Healthcare Funders expressing alarm at escalating healthcare costs and the integral part the private sector plays in this.

Health practitioners in private practice should have a fee structure as prescribed by their peers. I believe that this is the norm in other professions, and do not see why doctors should be treated differently. Fees may sometimes be dictated by harsh market forces of supply and demand, but certainly not by the Minister of Health, the Health Professions Council of South Africa, or the funding industry.

Patients are expected to pay a hefty monthly premium to an outside institution that promises to cover their medical costs. They unquestioningly accept this promise, but increasingly it remains unkept. However, promises broken by funders have mutated into overcharging by providers.

Although it is well publicised that medical aids are non-profit organisations, administrative profits seem to be the reason why medical aids such as Discovery are doing very successful business.

Has the time not come to stop the tired refrain of 'doctors overcharging' and focus on an industry that adds little of value to its members (patients) and is increasingly part of the problem rather than part of the solution?

Patients approach us for quotes, which are provided. This information can be studied and terms discussed with the service provider, a process generally well accepted by patients. When medical aid comes on the scene, patients expect it to cover everything and question why medical aid rates are not charged. The obvious response to this logic is that medical aids would probably not be impressed if doctors suggested monthly premiums they should charge!

In short: doctors and patients should discuss and negotiate fees between themselves. There is no need for medical aid assistance or interference. Patients entrust doctors with matters that may involve life or death. Maybe the Minister, the HPCSA and the BHF should trust us to write a fair account?

\section{Leon Groenveld}

Honeydew, Johannesbur

legro@iafrica.com

S Afr Med J 2013;103(1):7. DOI:10.7196/SAMJ.6428 